\title{
chę
}

\section{Mediação de conflitos no ambiente escolar para promover a cultura de paz}

\author{
Diana Elizabette Lima do Amaral \\ Mestra em Planejamento e Políticas Públicas - UECE \\ Jeannette Filomeno Pouchain Ramos \\ Doutora em Educação pela Universidade Federal do Ceará - UFC \\ Professora do Instituto de Humanidade e Letras (IHL) da UNILAB
}

\section{Resumo}

A mediação procura ensinar os membros da comunidade escolar a olhar as diferenças com respeito e tolerância, traçando novos caminhos na construção das relações e fortalecendo o diálogo e a paz. Assim, o lócus da pesquisa foi a Escola Estadual de Ensino Fundamental e Médio "Senador Osires Pontes", situada em uma região considerada violenta, uma das escolas piloto que compõem o projeto "Célula de Mediação Social e Cultura de Paz", desenvolvido pela Secretaria Estadual de Educação do Ceará (Seduc) com o propósito de aplicar técnicas de mediação para resolver conflitos e promover a cultura de paz. Analisamos as contribuições positivas e os desafios identificados após a implantação da mediação no ambiente escolar.

Palavras-chave escola; mediação; conflitos; cultura de paz.

\begin{abstract}
Mediation seeks to teach the school community members to look at differences with respect and tolerance, paving new paths to establish relationships and strengthening dialogue and peace. Thus, the locus of research was the Public State Elementary and High School Facility 'Senador Osires Pontes,' located in a region regarded as violent, one of the pilot schools that constitute the project 'Cell of Social Mediation and Culture of Peace,' developed by the Ceará State Department of Education (SEDUC) in order to apply mediation techniques for resolving conflicts and promoting the culture of peace. We analyze the positive contributions and the challenges identified after deploying mediation in the school environment.
\end{abstract}

Key words school; mediation; conflicts; culture of peace.

Conhecer: debate entre o público e o privado

2018, Vol. 08, n 21

ISSN 2238-0426

DOI: 10.32335/2238-0426.2018.8.21.1072

Licença Creative Commons Atribuição 


\section{Introdução}

O contexto escolar está concentrado em uma sociedade que exclui e não inclui, afetando diretamente os jovens que dela fazem parte. Os comportamentos e os valores da juventude mudaram, dificultando o relacionamento e a aprendizagem em sala de aula. Com essas transformações de identidade, o ambiente escolar se torna propício a divergências e enfrentamentos, movido por sentimentos de falta de solidariedade, falta de consciência, medo e insegurança, ao passo que o clima educativo deveria proporcionar satisfação a todos os envolvidos.

A família e a realidade social em que o aluno está inserido também influenciam o ambiente escolar, pois é por meio dessa bagagem coletiva que se constrói o bom relacionamento dentro da escola.

Diante desses pontos de partida, a mediação pode constituir uma alternativa para a solução de conflitos no ambiente escolar por representar uma técnica que promove o aprendizado social ao auxiliar na formação de um novo modelo de relacionamento entre as pessoas.

A mediação pode ser utilizada com todos os membros da comunidade escolar como uma alternativa de política pública. A implementação dessa intervenção não deve interferir na aprendizagem dos alunos, trata-se de uma ação adotada conforme as condições e as necessidades da escola considerando as relações envolvidas no conflito - docentes $x$ núcleo gestor, docentes $\mathrm{x}$ docentes, docentes $\mathrm{x}$ discentes, docentes $\mathrm{x}$ pais.

A principal proposta dessa técnica é resolver os conflitos de modo pacífico no ambiente escolar, tendo o diálogo entre as partes como elemento primordial nessa ação conduzida por uma terceira pessoa, que deve assumir uma postura imparcial. Justifica-se, assim, o objetivo deste artigo: analisar as contribuições positivas e os desafios identificados pela escola com a implantação da mediação para resolver conflitos e promover a cultura de paz.

\section{Um olhar sobre as juventudes e suas relações com o ambiente escolar}

A escola é um ambiente de constantes conflitos, devido às dificuldades de relacionamento com o jovem atual. Sposito (2003) reforça que a desarmonia entre o ambiente escolar e o universo juvenil gera perdas para todos os membros da comunidade escolar, pois não proporcionar espaços motivadores de aprendizado e vivências tende a causar desinteresse, indisciplina e apatia entre os jovens, abrindo caminho para as situações conflituosas. 
Por outro lado, as juventudes são dotadas de uma positividade que pode cooperar efetivamente na resolução de tais conflitos no ambiente escolar em vez de somente sofrêlos ou rejeitá-los (Matos, 2003, 2006, 2007).

Para Libâneo (2004, p. 19) a escola é "lugar de encontro e compartilhamento entre as pessoas [...] [para que] sejam acolhidos seus ritmos, suas diferenças", ou seja, a instituição escolar representa para esse jovem um espaço de relevância no desenvolvimento e na afirmação da sua existência. Porém, os crescentes conflitos que o cercam levam a vários questionamentos:

- A escola está preparada para lidar com as juventudes?

- É possível a diversidade de culturas e pensamentos no espaço escolar?

O termo juventudes evidencia duas vertentes: inicialmente, aquela que se constitui a partir do desenvolvimento biológico e psicológico do sujeito; já a segunda considera as juventudes sob o viés social, histórico e espacial. Nessa linha de pensamento, Cassab (2010, p. 40) enfatiza as juventudes "como categorias socialmente construídas, portanto, históricas e passíveis de mudanças no tempo e no espaço".

Um aspecto que chama a atenção quanto às juventudes é a formação de grupos com características derivadas de seus valores sociais, culturais e simbólicos. Desse modo, as juventudes não atuam apenas de maneira particular - elas assumem várias faces.

Sobre as juventudes e a formação de grupos, Esteves e Abramovay (2007, p. 25) expressam o seguinte comentário:

\footnotetext{
Existem muitos e diversos grupos juvenis, com características particulares e específicas, que sofrem influências multiculturais e que, de certa forma, são globalizados. Portanto, não há uma cultura juvenil unitária, um bloco monolítico, homogêneo, senão culturas juvenis, com pontos convergentes e divergentes, com pensamentos e ações comuns, mas que são, muitas vezes, completamente contraditórias entre si. [...] vivencia-se a condição juvenil de diferentes maneiras, em função das diferenças sociais e de parâmetros concretos, como o dinheiro, a educação, o trabalho, o lugar de moradia, o tempo livre etc. Logo, a definição da categoria juventude, em hipótese alguma, pode ser a mesma para todos aqueles que nela estão enquadrados.
}

A sociedade acaba impondo às juventudes a adoção de comportamentos e atitudes que se materializam em valores tradicionais. Essa postura permite a resistência das juventudes ao meio social e sua contestação por meio de ações negativas associadas à indisciplina, à violência, ao consumo de drogas.

As ações promovidas pela sociedade ao querer "moldar" os jovens, limitando suas atitudes e seus comportamentos, proporcionam a formação de cidadãos carregados de 
impotência, desigualdade e revolta, manifestando, muitas vezes, sentimentos nos espaços de sua convivência, como família e escola, gerando conflitos.

A conjuntura apresentada exige do Estado ações motivadoras, como realçado por Ramos (2005, p. 48):

\footnotetext{
Sendo assim, é fundamental o fomento de iniciativas, incentivando e valorizando a participação do cidadão comum, construindo condições, independentemente da renda ou posição social; como também é necessário que se reduzam as grandes diferenças a partir de uma pretensa igualdade econômica para assegurar a participação igualitária, e o Estado, novamente, tem um papel crucial no fomento de mecanismos e procedimentos adequados a esses meios e fins.
}

Segundo Abramo (1997), no Brasil, diferentemente de alguns países da Europa e dos Estados Unidos da América (EUA), não existe a prática de políticas públicas destinadas diretamente ao público jovem, principalmente ações voltadas apenas ao atendimento escolar. Para Trassi e Malvasi (2010), a criação de políticas públicas da juventude no Brasil ocorre somente com a articulação e o suporte dos movimentos estudantis, organizações não governamentais (ONGs) e setores da sociedade civil, como: a Declaração sobre o Fomento entre a Juventude dos Ideais de Paz, Respeito Mútuo e Compreensão entre os Povos, de 1965, da Organização das Nações Unidas (ONU); o Estatuto da Criança e do Adolescente (ECA), de 1990; o Programa de Ação Mundial para Jovens, de 1995, também da ONU; o Programa Brasil Jovem, de 1999, do Ministério da Previdência e Assistência Social; o Programa Agente Jovem de Desenvolvimento Social e Humano e o Projeto Centros de Juventude, de 2001; a Comissão Especial de Políticas Públicas para a Juventude, de 2003; o Programa Primeiro Emprego, de 2003; a Secretaria Nacional da Juventude, de 2005, vinculada à Secretaria Geral da Presidência da República; o Projovem, de 2005; e a 1aㅡ Conferência Nacional de Políticas Públicas de Juventude, de 2008.

Infelizmente, os projetos e os programas voltados a atender a população jovem ainda correspondem ao trabalho social de associações, instituições de assistência e ONGs (Trassi \& Malvasi, 2010). Abramo (1997, p. 26) ressalta que grande parte dessas ações se direciona aos jovens em situação de risco devido ao crime, às drogas e à exploração sexual. A intenção primordial dessas ações é a reintegração social desses jovens por meio de capacitação profissional e inserção no mercado de trabalho.

Nesse cenário, Trassi e Malvasi (2010, p. 24) destacam que, geralmente, as políticas públicas voltadas às juventudes se destinam apenas a envolver questões relativas ao trabalho, esquecendo a relação entre elas e a educação. Assim, o maior desafio é "considerar a esfera do desejo em suas múltiplas, criativas e expressivas possibilidades de produção e de participação social, que inclu[em] a diversidade e a alteridade". 
Sposito e Carrano (2003) advertem acerca da compreensão ambígua dos jovens, ora como cidadãos com direitos, ora como problema social, segundo a qual as políticas públicas acabam atuando passivamente diante desse público quando poderiam contribuir com eficiência na construção de novas formas de representação.

Entretanto, a efetivação de tais políticas públicas para as juventudes necessitam da articulação e comprometimento concreto de vários segmentos da sociedade e do Estado. Abramovay e Castro (2004, p. 99) destacam que:

\footnotetext{
Um problema particular é a inexistência de uma institucionalidade articuladora do trabalho governamental em nível federal, que poderia coordenar o trabalho das diferentes Secretarias de Estado e as experiências no plano estadual e municipal. Nesta mesma linha, é importante destacar, entre as matérias pendentes, a falta de algumas ferramentas de trabalho imprescindíveis, dentre as quais se destacam aquelas relacionadas com a geração de conhecimento, como: pesquisas de juventudes, estudos específicos e avaliação sistemática de experiências e programas.
}

Desse modo, ao enaltecer as juventudes enquanto problemática social, ajudamos a enxergá-las apenas sob essa ótica. É necessário reconstruir a visão negativa atribuída ao jovem e vê-lo como "potencial positivo" e "exempl[o] de revitalização social", detentor de um potencial mobilizador de transformações sociais (Matos, 2007, p. 65).

Nesse sentido, relacionar os jovens como problemática social induz a representáIos como ameaça à ordem social. Abramo (1997, p. 29) aborda essa concepção bastante discutida na sociologia como um período crítico vivenciado por eles em sua inserção social:

É nesse sentido que a juventude só está presente para o pensamento e para a ação social como "problema": como objeto de falha, disfunção ou anomia no processo de integração social; e, numa perspectiva mais abrangente, como tema de risco para a própria continuidade social.

A escola acaba representando um espaço gerador desses conflitos devido à grande concentração de jovens com diversos comportamentos e atitudes. Diante de tal diversidade cultural, mostra-se necessária profunda reflexão sobre os conflitos relacionais que cercam as juventudes e a escola.

Matos (2007) destaca a significância do diálogo, da escuta sensível, da construção de valores positivos nas escolas, do estímulo dos docentes a uma convivência pacífica, da afetividade e de projetos para e pela paz na consolidação dessas relações. 
A relação existente entre o jovem e a escola representa o processo em andamento sobre a compreensão de "ser jovem" e oferecer, em seu ambiente, vivências e conhecimentos destinados a esse público. Para Carrano (2000, p. 16),

[...] a escola sinaliza dificuldades de lidar com a diversidade que caracteriza esta juventude, sendo a homogeneidade muito mais desejável à cultura escolar do que a noção de heterogeneidade quer seja ela de faixa etária, de gênero, de classe, de cultura regional ou ética.

Esse contexto traz a figura das juventudes apenas como um momento de transição para a fase adulta, caracterizada por jovens sem opinião, anseio e atitudes próprias. Essa suposta falta de maturidade necessita de constante acompanhamento e controle para que não adentrem o mundo da violência e das drogas.

Entretanto, a ideia negativa construída sobre os jovens é contraditória, pois "ser jovem" é sinônimo de vitalidade, criatividade e dinamismo, contrapondo-se ao pensamento criado sobre delinquência e violência. Segundo Matos (2003, p. 32), é necessário direcionar o olhar às juventudes em busca de significados positivos: "amigos, futuro melhor, vida, responsabilidade e diversão, força, coragem, independência, passagem, melhor fase da vida, transição".

A escola necessita construir uma relação de diálogo com os jovens e sua realidade com a finalidade de oferecer espaços significativos de aprendizagem e vivências. Carrano (2007, p. 60) enfatiza que

[...] além das dificuldades de acesso e permanência na escola, os jovens enfrentam a realidade de instituições públicas que se orientam predominantemente para a oferta de conteúdos curriculares formais e considerados pouco interessantes pelos jovens. Isso implica em dizer que as escolas têm se apresentado como instituições pouco abertas para a criação de espaços e situações que favoreçam experiências de sociabilidade, solidariedade, debates públicos e atividades culturais e formativas de natureza curricular ou extraescolar.

A escola deve permitir que as juventudes atuem nesse ambiente de modo autônomo e transparente, sem seguir padrões pré-determinados pela sociedade, caracterizando sua essência em conformidade com sua origem social, econômica, política e, especialmente, cultural. Para S. M. N. Almeida (2009, p. 22), a contribuição da escola aos jovens vai além da mera transmissão de conteúdo: 
A escola deve cumprir o seu papel na sociedade, não só de transmissora de conhecimentos, mas realizando um trabalho em conjunto com outros setores da sociedade, possibilitando tempos e espaços para que a comunidade fale, reflita e pense soluções, e, sobretudo, aprendendo a ouvir seus alunos e considerar suas realidades sociais e culturais.

Os momentos vivenciados pelos jovens na escola possibilitam a construção de sentimentos identificados por diálogo, amizade, solidariedade e amor, devido à heterogeneidade nesse ambiente. Entretanto, a instituição escolar necessita acrescentar em seu currículo ações que agreguem o aspecto sociocultural com iniciativas para as juventudes expressarem livremente seus pensamentos. Segundo Dayrell (1996, p. 2):

\footnotetext{
São as relações sociais que verdadeiramente educam, isto é, formam, produzem os indivíduos em suas realidades singulares e mais profundas. Nenhum indivíduo nasce homem. Portanto, a educação tem um sentido mais amplo, é o processo de produção de homens num determinado momento histórico.
}

É essencial considerar a importância da atmosfera escolar na constituição das juventudes, pois, a partir do momento em que estão envolvidas em ambiente agradável, as relações são favorecidas.

\footnotetext{
A escola tornou-se um importante espaço de convivência e aprendizado para crianças e jovens, não só para prover os conteúdos educacionais tradicionais, mas, também, para que crianças e jovens se relacionem, adquiram valores e crenças, desenvolvam senso crítico, autoestima e segurança, mediadas pela figura de um adulto (Ruotti, Alves, \& Cubas, 2006, p. 14).
}

A escola, para muitos jovens, é um espaço considerado segunda casa. Nesse espaço físico, é fundamental que as juventudes possam ter um ambiente propício para convivência amistosa, descobertas e desenvolvimento de habilidades. A Lei de Diretrizes e Bases da Educação (LDB) enfatiza, em seu artigo 3를 inciso III, que o ensino deve seguir os princípios de pluralismo de ideias e de concepções pedagógicas, ou seja, a instituição escolar deve ter como finalidade contribuir não apenas para a qualidade das práticas educativas, mas para melhorar as relações e diminuir as divergências presentes nesse ambiente (Lei n. 9.394, 1996). 
Diante das divergências existentes na escola, decorrentes da falta de harmonia entre estudantes, nasce a necessidade de intervenções como a mediação para proporcionar a redução da violência e promover a cultura de paz. Desse modo, o próximo tópico enfatiza a mediação e os conflitos inerentes nas instituições escolares.

\section{Os reflexos da mediação para além da resolução do conflito}

A mediação se configura como um processo voluntário e confidencial em que aparece a figura de uma terceira pessoa, com características de imparcialidade e sociabilidade, que procura, por meio do diálogo, ajudar as pessoas envolvidas no conflito a alcançar uma solução reciprocamente aceitável diante do problema apresentado. No entanto, o conflito compreende uma resistência de interesses, podendo ser irremediável, mas, por meio da prática de intervenção, tal conflito pode ser totalmente solucionado, antecipado ou diminuído.

Segundo Vezzulla (1998, pp. 15-16), a mediação

[...] é a técnica privada de solução de conflitos que vem demonstrando, no mundo, sua grande eficiência nos conflitos interpessoais, pois com ela, são as próprias partes que acham as soluções. O mediador somente as ajuda a procurá-las, introduzindo, com suas técnicas, os critérios e os raciocínios que lhes permitirão um entendimento melhor.

Assim, a facilitação não pode ser compreendida como uma forma simplista na resolução de conflitos. Sua função vai além dessa prerrogativa, correspondendo a vários conceitos envolvidos, como: comunicação, acordo e transformação, sendo um espaço de escuta, diálogo e promoção da cidadania.

De acordo com Moore (1998, p. 28):

A mediação é geralmente definida como a interferência em uma negociação ou em um conflito de uma terceira parte aceitável, tendo um poder de decisão limitado ou não autoritário, e que ajuda as partes envolvidas a chegarem voluntariamente a um acordo, mutuamente aceitável com relação às questões em disputa. Além de lidar com questões fundamentais, a mediação pode também estabelecer ou fortalecer relacionamentos de confiança a respeito entre as partes ou encerrar relacionamentos de uma maneira que minimize os custos e danos psicológicos. 
Ainda sobre o mesmo tema, Morgado e Oliveira (2009, p. 48) reforçam a importância da neutralidade nesse método:

[...] uma negociação com a intervenção de um terceiro neutral, baseada nos princípios da voluntariedade das partes, da neutralidade e imparcialidade do terceiro (mediador) e na confidencialidade do processo, a fim de que as partes em litígio encontrem soluções que sejam mutuamente satisfatórias.

A interposição em conflitos procura obter como resultado final a promoção da convivência escolar entre as partes, permeando as relações interpessoais por meio do diálogo e da negociação na tomada de decisões. Esse método surgiu nas escolas como uma opção democrática para atenuar variadas situações que decorrem da violência no ambiente escolar.

S. M. N. Almeida (2009, p. 69) destaca que o processo de mediação:

[...] cria uma oportunidade para que as pessoas expressem suas emoções e esclareçam seus sentimentos. Depois de resolvida a confusão emocional, ou conflito de ordem subjetiva, as partes podem dedicar-se às questões objetivas ou quantificáveis e negociar, ficando mais simples e fácil encontrar as soluções que atendam a todos

Dentre as várias características exigidas do facilitador, o equilíbrio emocional e a metodologia utilizada na condução dos encontros são imprescindíveis para que a mediação seja tranquila e a qualidade das relações interpessoais seja preservada entre as partes.

Ortega e Del Rey (2002, p. 147) especificam que:

A mediação é a intervenção, profissional ou profissionalizada, de um terceiro um especialista - no conflito travado entre duas partes que não alcançam, por si mesmas, um acordo nos aspectos mínimos necessários para restaurarem uma comunicação, um diálogo que, é necessário para ambas [...] com o reconhecimento da responsabilidade individual de cada um no conflito e o acordo sobre como agir para eliminar a situação de crise com o menor custo de prejuízo psicológico, social ou moral para ambos os protagonistas e suas repercussões em relação a terceiros envolvidos. 
Desse modo, é importante enfatizar que não é qualquer pessoa que pode atuar como mediador - este deve apresentar características específicas para que a mediação seja positiva. O mediador deve saber escutar, favorecer o diálogo, apresentar equilíbrio emocional para não tomar parte no conflito e orientar o processo em clima harmônico e respeitoso entre os envolvidos.

De acordo com Warat (2001, pp. 76-77), o processo de conciliação corresponde a uma bússola, direcionando as partes, mas sem influenciar a decisão do caminho a seguir:

\footnotetext{
O mediador tem que ajudar cada pessoa do conflito para que elas o aproveitem como uma oportunidade vital, um ponto de apoio para renascer, falarem-se a si mesmas, refletir e impulsionar mecanismos interiores que as situem em uma posição ativa diante dos conflitos. O mediador estimula a cada membro do conflito para que encontrem, juntos, o roteiro que vão seguir para sair da encruzilhada e recomeçar a andar pela vida com outra disposição.
}

Nesse contexto, podemos enquadrar e compreender melhor as variadas concepções que envolvem a mediação, afastando o conceito inicial apenas como uma técnica empregada na resolução alternativa de conflitos, conferindo-lhe, também, visibilidade enquanto processo cooperativo e mesmo para a construção da cultura de paz.

Portanto, a atribuição do mediador se caracteriza como um instrumento destinado a facilitar o diálogo por meio de argumentos e questionamentos sobre o conflito de maneira sociável e pacífica entre as partes envolvidas. O facilitador, durante todo esse processo, deve manter uma postura imparcial e fomentar a comunicação entre os atores principais do conflito, a fim de amenizá-lo. Mostra-se relevante ressaltar que quem conduz a sessão é apenas o colaborador na tomada de decisões, sendo a responsabilidade final destinada aos envolvidos na questão.

Antes de introduzir o processo de conciliação no ambiente escolar, deve-se proceder a um diagnóstico para entender a dimensão da violência e as formas de solucioná-la. Além disso, também é imprescindível ter bem definidos os objetivos da proposta, para saber por onde iniciar e quando haverá resultado. Entretanto, mesmo com todo o planejamento da proposta, a mediação só poderá ser inserida na escola se esta for reconhecida como parte integrante de uma política pública e um projeto político-pedagógico da instituição.

Outro ponto significativo desse método se refere ao cuidado de resguardar a relação existente entre as partes, pois estas, na maioria das vezes, têm interesses comuns que foram abalados em determinado momento.

Assim, o mediador, durante o processo de conciliação, procura firmar um acordo que deriva da vontade das partes, não impondo sua opinião, ou seja, ele não julga, não 
aconselha e não acusa, tendo a sensibilidade de solucionar o problema da maneira mais justa, sem dano ou perda para qualquer uma das partes, não trazendo a prerrogativa da relação de perda e ganho entre os envolvidos.

Diante da relação entre ganhar e perder, Padilha (2004, p. 66) acrescenta:

\begin{abstract}
O processo de mediação visa [a] promover o diálogo entre as partes, propiciar a escuta diferenciada dos pontos de vista e razões da outra parte, num ambiente de respeito, levando à conscientização do realismo das próprias exigências. Tal conscientização gera responsabilidade, aumentando o compromisso com o acordo. Leva os envolvidos na disputa a saírem do círculo vicioso de vítima e bandido, da busca de culpados, e envolverem-se na tarefa de encontrar soluções, criando alternativas e chegando a acordos criativos para satisfazer as necessidades de todos os envolvidos no processo. Do padrão adversarial, no qual para que um ganhe é necessário que o outro perca, passa-se a um padrão cooperativo, no qual todos saem ganhando, ou seja, de uma negociação distributiva, de ganhar $x$ perder, passa-se a uma negociação integradora, de ganhar x ganhar.
\end{abstract}

A metodologia utilizada pelo facilitador na resolução do conflito consiste em pôr as partes em um mesmo nível, não fazendo nenhuma diferenciação entre elas, tendo o poder da escuta e da comunicação como elementos centrais na análise da situação geradora do conflito. Após a identificação dos pontos de controvérsia, conforme a história reproduzida por cada parte, o facilitador, com o consentimento de todos, busca a alternativa mais plausível para chegar a um acordo.

Vale ressaltar que cabe ao mediador adotar algumas ações para que o processo de mediação seja favorável, como: o número de reuniões possíveis; o tempo necessário para a sessão; a quantidade de pessoas que devem participar; o local; e, por fim, os meios essenciais para a elaboração do acordo. Sobre esse assunto, Buitoni (2010) assevera que

[...] não se envolve no conflito como se fosse ele uma das partes, mas sim sente o conflito em todas as suas dimensões, percorre o conflito, com os mediados nas suas sutilezas, para que sejam criados os novos caminhos que transcendam o conflito.

Ainda sobre o mesmo tema, Braga (2008, p. 79) fundamenta que

[...] a atuação do mediador, portanto, é, na vertente do auxílio na administração do conflito, a fim de promover como resultado a responsabilidade, não somente 
gerada na inter-relação existente ou que existia, mas, sobretudo, no que poderá ser construído no futuro a partir dele.

A mediação na escola não compreende somente a resolução de conflitos, mas também a prevenção. Portanto, é primordial a sensibilização de todos para a compreensão do processo de mediação, pois esta representa mais do que uma simples técnica - indica um projeto educativo, ou seja, um novo olhar para enxergar a problemática que circula o ambiente escolar, promovendo a cultura de paz.

O contexto que envolve a mediação na resolução de conflitos também se relaciona com a cultura de paz, pois ambas suscitam a convivência respeitosa das juventudes. Essa relação propicia maior sensibilidade e consciência de atitude e fatos do ambiente escolar, bem como transformam as relações interpessoais (Matos, Castro, \& Nascimento, 2008).

Diante dos inúmeros atritos enfrentados pelos jovens na sociedade atual, a escola deve procurar desenvolver projetos destinados à promoção da cultura de paz com a finalidade de propagar sentimentos de tolerância e respeito mútuo. Segundo Matos (2010, p. 27), "o acompanhamento contínuo dos projetos estimula o respeito e a tomada de decisões acertadas entre a escola e a comunidade, e consolida a paz ativa nesse lócus".

A implantação de projetos na escola com esse propósito direciona os jovens a refletir sobre o que é a paz, bem como suas ações e atitudes diante de situações que envolvem conflitos. Desse modo, a promoção da paz deve ser construída de forma coletiva, com o envolvimento de todos os membros da comunidade escolar. Matos, Castro e Nascimento (2008, p. 24), salientam que "o compromisso dos professores e da gestão é de fundamental relevância para o desenvolvimento dos projetos e a consolidação da disseminação da Cultura de Paz".

A escola se torna um aparelho para aprender, tendo de apresentar excelentes índices de desempenho dos alunos aos órgãos superiores. Assim, os jovens se tornam objeto de manipulação e condicionamento. Tudo o que não corresponde às normas e regras ditadas pelo sistema deve ser penalizado e reprimido. Alguns mecanismos de dominação são utilizados até hoje por algumas escolas para moldar o aluno, como filas, horários e avaliações, dentre outros.

O exame combina as técnicas da hierarquia que vigia e as da sanção que normaliza. É um controle normalizante, uma vigilância que permite qualificar, classificar e punir. Estabelece sobre os indivíduos uma visibilidade através da qual eles são diferenciados e sancionados. É por isso que em todos os dispositivos de disciplina o exame é altamente ritualizado. Nele vêm-se reunir a cerimônia do poder e a forma da experiência, a demonstração da força e o estabelecimento da verdade. 
No coração dos processos de disciplina, ele manifesta a sujeição dos que são percebidos como objetos e a objetivação dos que se sujeitam. A superposição das relações de poder e das de saber assume no exame todo o seu brilho visível (Foucault, 1977, pp. 164-165).

Todos esses aspectos facilitam a existência de embates, sendo inevitável à condição humana, "o conflito é o estado natural do homem" (Mendel, 1974, p. 13). Embora o problema represente uma parte construtiva da vida, em todas as suas dimensões, continua a ter uma implicação negativa em nossa sociedade.

Á. Chrispino e R. S. P. Chrispino (2011, p. 38) destacam que o conceito de conflito geralmente advém de alguma discordância cujos interesses correspondem a posicionamentos opostos:

O conflito é parte integrante da vida e da atividade social, quer contemporânea, quer antiga. Ainda no esforço de entendimento do conceito, podemos dizer que o conflito se origina da diferença de interesses, de desejos e de aspirações. Percebe-se que não existe aqui a noção estrita de erro e de acerto, mas de posições que são defendidas frente a outras, diferentes.

Para A. R. S. Almeida (2001, p. 85) "o conflito faz parte da natureza, da vida das espécies, porque somente ele é capaz de romper estruturas prefixadas, limites predefinidos. O conflito atinge os planos sociais, morais, intelectuais e orgânicos", ou seja, estes são significativos para a construção da personalidade.

Chiavenato (1987, pp. 88-89) reforça o conceito em questão:

[...] significa a existência de ideias, sentimentos, atitudes ou interesses antagônicos que se podem chocar. Sempre que se fala em acordo, aprovação, coordenação, resolução, unidade, consentimento, harmonia, deve-se lembrar que essas palavras pressupõem a existência ou a eminência dos seus opostos, como desacordo, desaprovação, desentendimento, incongruência, discordância, inconsistência, oposição - o que significa conflito.

Desse modo, o conflito representa um fenômeno natural, que aparece entre dois ou mais indivíduos, como enfatiza Torrego (2003), que enxerga tais rivalidades como situações em que duas ou mais pessoas entram em divergência por motivos diversos, dentre eles: interesses, necessidades, desejos, posicionamento de ideias e valores. 
Todos estes conceitos retratam o embate como parte associada à vida, como também ao ambiente social decorrente da diferença de interesses, desejos e aspirações. Assim, não existe a ideia restritiva de erro ou de acerto, mas de posicionamentos contrários defendidos diante de outros.

Por mais que a definição de conflito direcione a uma perspectiva negativa, ele apresenta elementos positivos. Apesar de instigar a divergência e reprimir a cooperação em seu aspecto negativo, por outro lado, pode corresponder a um momento de mudança no processo da sua resolução. Á. Chrispino (2007, p. 18) aponta algumas vantagens que podem ocorrer aos sujeitos envolvidos no atrito após sua resolução:

\footnotetext{
O conflito é inevitável e não se devem suprimir seus motivos, até porque ele possui inúmeras vantagens dificilmente percebidas por aqueles que veem nele algo a ser evitado: ajuda a regular as relações sociais; ensina a ver o mundo pela perspectiva do outro; permite o reconhecimento das diferenças, que não são ameaça, mas resultado natural de uma situação em que há recursos escassos; ajuda a definir as identidades das partes que defendem suas posições; permite perceber que o outro possui uma percepção diferente; racionaliza as estratégias de competência e de cooperação; ensina que a controvérsia é uma oportunidade de crescimento e de amadurecimento social.
}

Segundo Pallarés (1983), o conflito em si não indica crueldade ou ação desumana, embora as partes envolvidas possam apresentar atitudes que assumem formas prejudiciais, isto é, a resposta não na extinção do problema, mas em sua normalização, resolução pacífica, respeitável e justa. Trata-se de empregar técnicas aplicáveis, ressaltando as estratégias para a solução pacífica, tranquila e conciliadora.

Sobre o tema, S. M. N. Almeida (2009, p. 39) assegura que

[...] os conflitos devem ser percebidos numa perspectiva de totalidade, aprendendo-se os diversos aspectos, relações e inter-relações neles presentes e propondo situações que sejam inclusivas. Essas alternativas de resolução de conflitos orientam-se mediante os princípios: cooperação, solidariedade, igualdade e respeito, com vistas à construção de um ambiente eficaz para as relações.

Morgado e Oliveira (2009, p. 43) destacam a significância do conflito como fator positivo na construção de mudanças: 


\begin{abstract}
Os programas de resolução de conflitos partilham princípios básicos. O conflito é tomado como uma dimensão natural e inevitável da existência humana que, se for conduzido eficazmente, pode constituir uma importante experiência de desenvolvimento pessoal. A aprendizagem de competências de resolução de problemas deve, assim, constituir uma oportunidade para os indivíduos construírem soluções mais positivas e mais pacíficas para os seus conflitos.
\end{abstract}

Entretanto, há dificuldade para identificar o conflito e as circunstâncias que o geraram, em que somente são percebidos por meio de situações envolvidas por ações violentas. Á. Chrispino e R. S. P. Chrispino (2011, p. 38) afirmam que "o conflito só é percebido quando produz manifestações violentas".

Diante desse pensamento, Ortega e Del Rey (2002, p. 143) declaram que:

O conflito emerge em toda situação social em que se compartilham espaços, atividades, normas e sistemas de poder e a escola obrigatória é um deles. Um conflito não é necessariamente um fenômeno da violência, embora, em muitas ocasiões, quando não abordado de forma adequada, pode chegar a deteriorar o clima de convivência pacífica e gerar uma violência multiforme na qual é difícil reconhecer a origem e a natureza do problema.

Anteriormente à efetivação do atrito, alguns sinais são emitidos, incidindo no confronto de interesses, comportamentos ou ideias. No entanto, muitas vezes, tais sinais não são identificados com antecedência a fim de promover ações de prevenção. Á. Chrispino (2007, p. 16) destaca "a nossa incapacidade de identificar as circunstâncias que derivam do conflito ou redundam nele".

O ser humano, apesar de vivenciar ao longo de sua vida várias situações envolvendo conflitos, não está pronto para proceder de modo correto no momento exato em que eles ocorrem. Assim, o ideal é que sejam resolvidos com a condução correta de um profissional da área de mediação o quanto antes, pois acabam retornando muitas vezes com maior intensidade, gerando novos problemas.

No universo da escola, várias situações acabam ocasionando embates entre os diversos membros da comunidade escolar (alunos, professores, gestores, funcionários e pais), seja por divergência de opinião ou dificuldade de comunicação, dentre outros motivos, mas com destaque para a ausência do diálogo.

Tocqueville (2001) enfatiza a responsabilidade da escola na condução do cidadão para o exercício da cidadania. O grande destaque de seu pensamento corresponde à utilização correta e responsável do direito à liberdade, que estaria ligado a atuar de modo 
ativo, expondo sua opinião, participando de debates e aprendendo com a experiência dessa ação política.

A prática da mediação proporciona alterações no contexto escolar; tais mudanças podem ser positivas, por proporcionar novas formas e métodos na resolução de atritos, ou negativas, quando desconsideram todas as ações desenvolvidas pela escola até então, modificando-as drasticamente. No entanto, a mediação escolar, ao invés de descartar os métodos adotados pela escola na solução de contendas, conduz a reflexão sobre como esses métodos são empregados e agrega novos dispositivos que tornem igualitária a tomada de decisões. Schnitman e Littlejohn (1999, p. 19) declaram:

\footnotetext{
As metodologias para a resolução de conflitos podem ser definidas como práticas emergentes que operam entre o existente e o possível. À luz de novos paradigmas, tais processos emergentes podem ser entendidos como processos auto-organizativos em sistemas complexos, processos nos quais os participantes, ao construírem renovadas possibilidades na resolução de seus conflitos, reconstroem suas relações e reconstroem a si mesmos.
}

Portanto, para que o processo de mediação obtenha sucesso no espaço escolar se mostra importante que o currículo contemple a cultura de paz. A mediação atua como uma possibilidade que, dentre outras, pode tornar possível a resolução de problemas entre os próprios envolvidos, com a presença de um facilitador, evitando, dessa forma, que sejam exercidas relações de poder.

Os programas de mediação de conflitos possuem sua origem fora do ambiente escolar, no entanto, seu modelo foi rapidamente adaptado à realidade educacional.

As ações referentes à mediação escolar, no momento atual, são intensificadas pelo Governo do Estado do Ceará por meio do trabalho voltado a uma cultura de paz e construção de valores com a criação do projeto "Célula de Mediação Social e Cultura de Paz", ligada à Coordenação de Protagonismo Estudantil, cuja finalidade principal é a prevenção da violência no ambiente escolar, proporcionando às juventudes um espaço seguro, aconchegante e favorável ao desenvolvimento humano e social.

Essa ação resulta do termo de cooperação assinado em abril de 2013 entre a ONG Terre des hommes (Tdh), o Ministério Público do Estado do Ceará (MPCE) e a Secretaria Estadual de Educação do Ceará (Seduc), com fins de implantar o Programa de Mediação Escolar, provendo o aporte técnico necessário à capacitação de gestores, professores, profissionais de ensino e alunos para atuarem como mediadores em situações de conflito que surjam no ambiente escolar.

A "Célula de Mediação Social e Cultura de Paz", além de constituir um auxílio para as escolas públicas estaduais na redução de situações envolvendo conflitos, também 
contribui com as ações do Pacto por um Ceará Pacífico, referente a atividades destinadas à prevenção da violência e à diminuição da criminalidade.

A implantação dessa ação promovida pela Seduc conta com a colaboração de algumas entidades, com o intuito de promover uma cultura de paz, dentre elas: a Coordenadoria de Articulação e Mediação Social; a Vice-Governadoria; o MPCE; a Associação Terre des hommes.

Os projetos que envolvem a mediação permitem enxergar o conflito de modo positivo, como oportunidade de aprendizagem e crescimento, por meio de gestão democrática, promovendo o diálogo e a escuta para a inserção de ações voltadas à cultura de paz no ambiente escolar (Morgado \& Oliveira, 2009).

Desse modo, o lócus da pesquisa se direcionou ao estudo de caso na Escola Estadual de Ensino Fundamental e Médio (EEEFM) "Senador Osires Pontes", situada na R. Divina, 150, Canindezinho, Fortaleza-CE. A escolha dessa escola para a pesquisa decorreu do fato dela ser uma das escolas piloto que compõem o projeto "Célula de Mediação Social e Cultura de Paz", desenvolvido pela Seduc e primeira instituição da rede estadual de ensino da cidade a apresentar uma sala de mediação.

Vale ressaltar que a escola em questão se situa em uma região considerada violenta, segundo: o Laboratório de Direitos Humanos, Cidadania e Ética da Universidade Estadual do Ceará (LabVida/UECE); o Laboratório de Estudos da Conflitualidade da Universidade Estadual do Ceará (COVIO-UECE); e o Laboratório de Estudos da Violência da Universidade Federal do Ceará (LEV-UFC). Trata-se de um dos cinco bairros que integram o Grande Bom Jardim (junto com Bom Jardim, Siqueira, Granja Portugal e Granja Lisboa), com altas taxas de homicídios - 61 registros em 2009, número superior ao dos anos de 2007 (49 homicídios) e 2008 (39 homicídios) -, bem como também de relações conflituosas: houve 214 casos em 2007, 185 em 2008 e 256 em 2009, reforçando a necessidade de ações voltadas à mediação e à cultura de paz.

Essas informações reforçam a relevância de conhecer e analisar essa escola, com o intuito de verificar, por meio dos dados coletados, as contribuições da técnica de mediação para a comunidade escolar.

Para contribuir de modo significativo, utilizou-se a análise qualitativa. Dentre os métodos de coleta de dados adotados na pesquisa qualitativa, destacamos a entrevista semiestruturada e a observação. Em um primeiro momento, o método da coleta de dados compreendeu a observação direta, proporcionando momentos de análise dos comportamentos e das condições do ambiente escolar. Nessa fase são observados os comportamento dos alunos e dos professores e a atuação da gestão, dentre outras atividades relacionadas ao objetivo da pesquisa.

Já no segundo momento foram realizadas 6 entrevistas semiestruturadas, com: 1 coordenadora pedagógica; 1 mediadora; 2 professores; e 2 alunas que participaram em 
algum momento da mediação escolar. Todas as entrevistas tiveram a finalidade de investigar como os membros da comunidade escolar compreendem o processo de mediação e o incorporam à sua vida cotidiana.

No momento da entrevista, selecionamos perguntas abertas, segundo uma ordem pré-determinada. Elas foram reformuladas a partir das respostas dos entrevistados.

Assim, as entrevistas enfocaram três tópicos a observar na pesquisa: identificar os tipos de conflitos mais frequentes na escola; verificar se as técnicas de mediação contribuem para atender às demandas conflitivas do ambiente escolar; e analisar como os membros da comunidade escolar (alunos, professores e núcleo gestor) percebem esse fenômeno.

Diante de todos os dados colhidos por meio da observação e das entrevistas, tornou-se nítida a preocupação da equipe gestora em manter e melhorar o clima escolar voltado à cultura de paz por meio da gestão democrática, motivando e envolvendo todos para esse fim. Por outro lado, a mudança positiva de atitude de alunos e professores em relação ao outro reforça a importância da mediação para a redução e a resolução de conflitos, além de contribuir para intensificar os relacionamentos interpessoais.

Desse modo, pode-se afirmar que a mediação é:

[...] induzir a uma reorientação das relações sociais, a novas formas de cooperação, de confiança e de solidariedade; formas mais maduras, espontâneas e livres de resolver as diferenças pessoais ou grupais. A mediação induz atitudes de tolerância, responsabilidade e iniciativa individual que podem contribuir para uma nova ordem social (Á. Chrispino, 2007, pp. 23-24).

\section{Considerações finais}

A implantação da mediação no ambiente escolar não é um processo fácil, pois exige da equipe gestora determinação para sua condução e a sensibilização do grupo de docentes e discentes na mudança de postura ao enxergar o outro. A escola está inserida em uma sociedade que mais exclui do que inclui, atingindo diretamente o comportamento dos jovens que acabam, muitas vezes, refletindo angústias, medos e decepções, dentre outros sentimentos no espaço escolar. Assim, a mediação representa uma forma de intervir na conduta dos membros da escola, contribuindo com a formação de cidadãos para o convívio em sociedade.

Sob essa perspectiva, a mediação traz para o âmbito escolar uma contribuição significativa na redução e resolução dos conflitos, além de transformar esses conflitos em oportunidades de aprendizagem e amadurecimento para as partes envolvidas. É necessário 
entender que $\mathrm{o}$ ato de mediar requer o conhecimento das técnicas relacionadas ao assunto da mediação destinada à atuação de um profissional competente da área que, por meio de uma postura imparcial, utiliza o diálogo como elemento primordial na resolução do conflito.

Verificamos que a EEEFM "Senador Osires Pontes" teve considerável redução nas situações que envolviam conflitos e violência, destinando-se atualmente a casos de indisciplina. Com isso, a mediação proporcionou à escola não apenas a resolução dos conflitos, mas também a mudança de comportamento e atitude da maioria dos membros da comunidade escolar, o fortalecimento das relações interpessoais e a intensificação de alguns valores, como a tolerância e o respeito ao próximo, promovendo um ambiente agradável. Contudo, alguns desafios são enfrentados diariamente pela equipe gestora para preservar a cultura de paz na escola, como a resistência de alguns docentes ao projeto, a escassez de materiais de esporte e lazer e o empenho desses docentes em mantê-lo sempre ativo e atuante.

Constatamos que a equipe gestora intensificou a atuação democrática por meio de ações voltadas ao diálogo e à participação ativa da comunidade escolar nas decisões coletivas da escola, procurando preservar o clima escolar conquistado com a implantação do projeto de mediação na escola. Já os docentes procuraram rever seu fazer pedagógico em sala de aula, com um olhar voltado à aprendizagem e às dificuldades dos alunos, não somente ao repasse dos conteúdos, respeitando os limites desses alunos. Assim, os discentes aumentaram seu interesse pelas disciplinas, apresentando resultados positivos referentes às notas, reduzindo consideravelmente a quantidade de alunos reprovados após a implantação da mediação.

Concluímos que a escola, por intermédio da mediação, tem conseguido obter resultados positivos não somente na melhoria do clima escolar entre os membros da comunidade, mas na aprendizagem dos estudantes, com um olhar mais atento e cuidadoso por parte dos professores diante das metodologias de ensino utilizadas para a transmissão dos conteúdos.

\section{Referências bibliográficas}

Abramo, H. W. (1997). Considerações sobre a tematização social da juventude no Brasil. Revista Brasileira de Educação, 1997(5-6), 25-36.

Abramovay, M., \& Castro, M. G. (2004). Políticas de/para/com juventudes. Brasília, DF: Organização das Naç̃̃es Unidas para a Educação, a Ciência e a Cultura.

Almeida, A. R. S. (2001). A emoção na sala de aula. São Paulo, SP: Papirus.

Almeida, S. M. N. (2009). Avaliação das concepções da violência no espaço escolar e mediação de conflitos (Tese de Doutorado). Universidade Federal do Ceará, Fortaleza, CE.

Braga, A., Neto. (2008). O que é mediação de conflitos. São Paulo, SP: Brasiliense. 
Buitoni, A. (2010, novembro). Mediar e conciliar: as diferenças básicas. Recuperado de jus.com.br/ artigos/17963/mediar-e-conciliar-as-diferencas-basicas

Carrano, P. C. R. (2000, novembro). Identidades juvenis e escola. Alfabetização e Cidadania, 2000(10), 9-19.

Carrano, P. C. R. (2007). Educação de Jovens e Adultos e juventude: o desafio de compreender os sentidos da presença dos jovens na escola da "segunda chance". Revista de Educação de Jovens e Adultos, 2007(1), 55-67.

Cassab, C. (2010). Refazendo percursos: considerações acerca das categorias jovem e juventude no Brasil. Perspectiva, 34(128), 39-51.

Chiavenato, I. (1987). Teoria geral da administração. São Paulo, SP: McGraw Hill.

Chrispino, Á. (2007). Gestão do conflito escolar: da classificação dos conflitos aos modelos de mediação. Ensaio: Avaliação e Políticas Públicas em Educação, 15(54), 11-28.

Chrispino, Á., \& Chrispino, R. S. P. (2011). A mediação do conflito escolar. São Paulo, SP: Biruta.

Dayrell, J. (Org.). (1996). Múltiplos olhares sobre educação e cultura. Belo Horizonte, MG: Ed. UFMG.

Esteves, L. C. G., \& Abramovay, M. (2007). Juventude, juventudes: pelos outros e por elas mesmas. In M. Abramovay, E. R. Andrade, \& L. C. G. Esteves (Orgs.), Juventudes: outros olhares sobre a diversidade (pp. 19-54). Brasília, DF: Organização das Nações Unidas para a Educação, a Ciência e a Cultura. Foucault, M. (1977). Vigiar e punir. Petrópolis, RJ: Vozes.

Lei n. 9.394, de 20 de dezembro de 1996. (1996). Estabelece as diretrizes e bases da educação nacional. Recuperado de http://portal.mec.gov.br/seesp/arquivos/pdf/lei9394_ldbn1.pdf

Libâneo, J. C. (2004). Entrevista com José Carlos Libâneo. Revista Plurais, 1(1), 9-35.

Matos, K. S. A. L. (2003). Juventude, professores e escola: possibilidades de encontros. Ijuí, RS: Ed. Unijuí.

Matos, K. S. A. L. (2006). Vivência de paz: o Reiki na escola Parque 210/211 Norte em Brasília. In M. C. A. Bomfim, \& K. S. A. L. Matos (Orgs.), Juventude, culturas de paz e violência nas escolas (pp. 15-32). Fortaleza, CE: Ed. UFC.

Matos, K. S. A. L. (2007). Juventudes e cultura de paz: diálogos de esperança. In A. C. Pinto, C. J. S. Araújo, \& H. L. Costa (Orgs.), Formação do pesquisador em educação: questões contemporâneas (pp. 215 - 224). Maceió, AL: Ed. Ufal.

Matos, K. S. A. L. (2010). A paz que protege: cultura de paz, juventudes e docentes. In K. S. A. L. Matos, \& R. Nonato, Junior (Orgs.), Cultura de paz, ética e espiritualidade (pp. 19-30). Fortaleza, CE: Ed. UFC.

Matos, K. S. A. L., Castro, L. M. D., \& Nascimento, E. L. (2008). Semeando a paz: escolas e sujeitos em busca de valores. In K. S. A. L. Matos, V. S. Nascimento, \& R. Nonato, Junior (Orgs.), Cultura de paz: do conhecimento à sabedoria (pp. 17 - 29). Fortaleza, CE: Ed. UFC. 
Mendel, G. (1974). La descolonización del niño. Barcelona, España: Ariel.

Moore, C. W. (1998). O processo de mediação: estratégias práticas para a resolução de conflitos (2a ed.). Porto Alegre, RS: Artmed.

Morgado, C., \& Oliveira, I. (2009). Mediação em contexto escolar: transformar o conflito em oportunidade. Revista Exedra, 2009(1), 43-55.

Ortega, R., \& Del Rey, R. (2002). Estratégias educativas para prevenção das violências. Brasília, DF: Organização das Nações Unidas para a Educação, a Ciência e a Cultura.

Padilha, R. D. (2004). Mediação sistêmico-integrativa: família e escola construindo uma cultura de paz. Curitiba, PR: Amanapaz.

Pallarés, M. (1983). Técnicas de grupo para educadores. Madrid, España: ICCE.

Ramos, J. F. P. (2005). Gestão democrática da escola pública: a experiência do governo das mudanças (1995-2001). Fortaleza, CE: Ed. UECE.

Ruotti, C., Alves, R., \& Cubas, V. O. (Orgs.). (2006). Violência na escola: um guia para pais e professores. São Paulo, SP: Andhep.

Schnitman, D. F., \& Littlejohn, S. (Orgs.). (1999). Novos paradigmas da mediação. Porto Alegre, RS: Artmed.

Sposito, M. P. (2003). Os jovens no Brasil: desigualdades multiplicadas e novas demandas políticas. São Paulo, SP: Ação Educativa.

Sposito, M. P., \& Carrano, P. (2003). Juventude e políticas no Brasil. Revista Brasileira de Educação, 2003(24), 16-39.

Tocqueville, A. (2001). A democracia na América. São Paulo, SP: Martins Fontes.

Torrego, J. (2003). Mediação de conflitos em instituições educativas: manual para formação de mediadores. Porto, Portugal: Asa.

Trassi, M. L., \& Malvasi, P. A. (2010). Violentamente pacíficos: desconstruindo a associação juventudes e violência. São Paulo, SP: Cortez.

Vezzulla, J. C. (1998). Teoria e prática da mediação. Curitiba, PR: Instituto de Mediação e Arbitragem do Brasil.

Warat, L. A. (2001). O ofício do mediador. Florianópolis, SC: Habitus. 